\title{
Plasma 17OH-progesterone concentrations in newborn infants
}

\author{
I. A. HUGHES, D. RIAD-FAHMY, AND K. GRIFFITHS \\ Tenovus Institute and Department of Child Health, Welsh National School of Medicine, Cardiff
}

SUMMARY Plasma concentrations of $170 \mathrm{H}$-progesterone were determined in 60 normal newborn infants aged between 3 and 36 hours. Mean levels decreased rapidly during this time after removal of the placental contribution of this steroid. A further 70 normal infants, studied between ages 2 and 7 days, showed a mean plasma $17 \mathrm{OH}$-progesterone concentration of $3.5 \mathrm{nmol} / 1(1.2 \mathrm{ng} / \mathrm{ml})$. By comparison, plasma concentrations in untreated infants with congenital adrenal hyperplasia were markedly raised. At 36 hours of age, there was an obvious difference between plasma levels of this steroid in normal and affected infants. Determination of plasma $170 H$-progesterone concentrations are valuable in the evaluation of disorders of sexual differentiation and electrolyte balance in newborn infants, provided due care is given to the timing of sample collections.

It is now well established that plasma concentrations of $17 \mathrm{OH}$-progesterone are markedly raised in untreated congenital adrenal hyperplasia (CAH) due to C-21 hydroxylase enzyme deficiency (Barnes and Atherden, 1972; Youssefnejadian and David, 1975; Hughes and Winter, 1976). Consequently, requests for measuring this steroid in plasma collected from newborn infants with ambiguous genitalia are increasing in frequency. The Supraregional Assay Service Laboratory at the Tenovus Institute receives numerous blood samples each week for determination of plasma $170 \mathrm{H}$-progesterone concentrations. Many of these samples have been collected within the first 48 hours of life at a time when, because of placental $170 \mathrm{H}$-progesterone production (Tulchinsky and Simmer, 1972), plasma concentrations are raised in normal newborn infants. There is a limited amount of information on plasma concentrations of $170 \mathrm{H}-$ progesterone during early life and on the time taken for levels to decrease to values observed in later infancy and childhood. This report gives data on plasma $17 \mathrm{OH}$-progesterone concentrations in mixed cord blood and in a group of normal newborn infants studied during early postnatal life. The results are compared with those found in untreated newborn infants with CAH.

Tenovus Institute and Department of Child Health, Welsh National School of Medicine, Cardiff

I. A. HUGHES, research fellow

D. RIAD-FAHMY, principal biochemist

K. GRIFFITHS, director, Tenovus Institute

\section{Patients and methods}

Mixed cord blood samples were obtained from 19 babies ( 10 boys and 9 girls) immediately after cord clamping. Their gestational ages ranged from 37 to 41 weeks. Capillary blood was collected by heel prick from 60 infants who were products of uneventful term pregnancies. There were 32 boys and 28 girls, whose postnatal ages ranged from 3 to 36 hours at the time of sample collection. Maternal consent for the study was obtained in each case. Plasma samples collected from 70 infants up to 7 days' postnatal age and sent to this laboratory were also available for analysis. Several infants with $\mathrm{CAH}$ due to $\mathrm{C}-21$ hydroxylase deficiency were studied during the first week of life before starting steroid replacement therapy. Their plasma 170H-progesterone concentrations were compared with those determined in normal infants.

Plasma 17OH-progesterone was measured by radioimmunoassay (RIA) using an antiserum kindly donated by Dr D. L. Loriaux, NIH, Bethesda. The sensitivity of the assay was $4 \mathrm{pg} /$ tube using $200 \mu \mathrm{l}$ plasma. Apart from 11-deoxycortisol (3.3\%) and 21-deoxycortisol $(1.6 \%)$, the cross-reactivity of the $17 \mathrm{OH}$-progesterone antiserum with numerous other steroids, including progesterone, was less than $0.1 \%$ The intra-assay coefficient of variation was $\pm 6 \cdot 3 \%$; the inter-assay coefficient of variation was $\pm 7.5 \%$ (high pool) and $11.9 \%$ (low pool). All RIA data processing was performed using the method of 
Rodbard and Hutt (1974) and quality controlled by the method of Kemp et al. (1978). The mathematical relationship between plasma concentration $(\mathrm{Y})$ and the age of the newborn infant $(t)$ was reasonably described by a power function of the form $Y=A t^{B}$ within the time-span of sampling. The index of determination was 0.72 and values of $A$ and $B$ determined by least squares analysis of data contained in Fig. 1, using a linear transformation of this equation, were 151 and -0.906 respectively.

\section{Results}

Mean values for plasma $17 \mathrm{OH}$-progesterone concentrations in mixed cord blood were $203 \pm 37 \cdot 8 \mathrm{SD}$ $\mathrm{nmol} / \mathrm{l}(69 \pm 12 \cdot 9 \mathrm{ng} / \mathrm{ml})$ for boys and $184 \pm 34 \cdot 5$ SD $\mathrm{nmol} / \mathrm{l}(62.6 \pm 11 \cdot 7 \mathrm{ng} / \mathrm{ml})$ for girls. There was no significant sex difference. The individual plasma

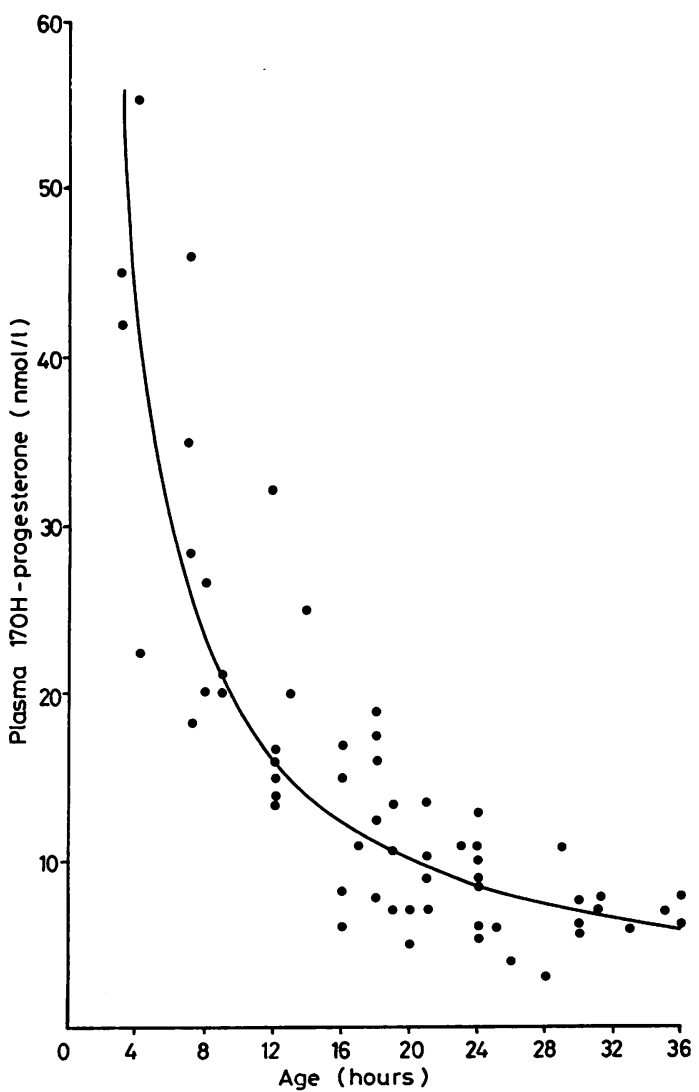

Fig. 1 Plasma 170H-progesterone concentrations in normal infants during the first 36 hours of life. The line represents the mean plasma concentration of this steroid in baby boys and girls.

Conversion: SI to traditional units-170H-progesterone: $1 \mathrm{nmol} / 1 \approx 0.31 \mathrm{ng} / \mathrm{ml}$.
170H-progesterone concentrations for 60 newborn infants in relation to postnatal age are shown in Fig. 1. The line represents the mean plasma $170 \mathrm{H}-$ progesterone concentration for the whole group of infants, there being no significant difference between mean concentrations in boys and girls. The mean plasma $170 \mathrm{H}$-progesterone concentration fell rapidly after birth, from $45 \mathrm{nmol} / \mathrm{l}(16 \mathrm{ng} / \mathrm{ml})$ at 12 hours, to $8.5 \mathrm{nmol} / 1(2.9 \mathrm{ng} / \mathrm{ml})$ at $24 \mathrm{hours}$, and $6 \mathrm{nmol} / 1$ $(2 \mathrm{ng} / \mathrm{ml})$ by 36 hours of age. This represents a 32 fold decrease from the mean cord plasma $170 \mathrm{H}-$ progesterone concentration. The pattern of plasma $170 H$-progesterone concentrations in normal infants during the first week of life is shown in Fig. 2. Mean levels reached a nadir of about $3 \cdot 5 \mathrm{nmol} / 1(1 \cdot 2 \mathrm{ng} / \mathrm{ml})$ by 7 days of age. This contrasts with plasma $17 \mathrm{OH}-$ progesterone concentrations in untreated $\mathrm{CAH}$ infants during the first 7 days of life. At 12 hours' postnatal age, there was a wide difference between plasma 170H-progesterone concentrations in normal and $\mathrm{CAH}$ infants. By the 2 nd day there was a 40 -fold

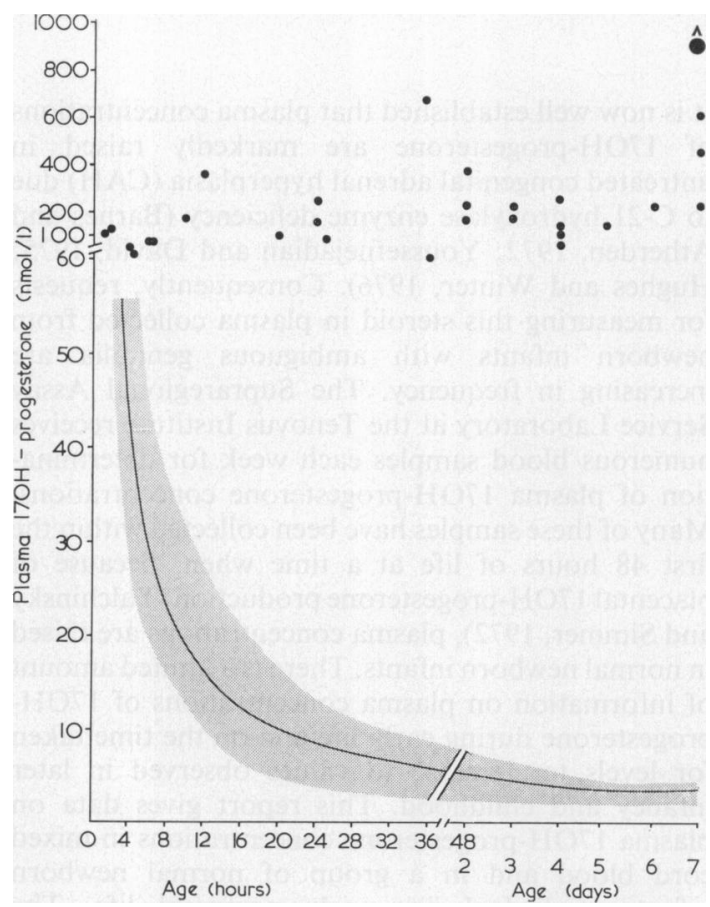

Fig. 2 Plasma 17OH-progesterone concentrations in normal and $C A H$ infants during the first 7 days of life. The line represents the mean and the shaded area encompasses the range of plasma concentrations in normal babies. Also shown are individual plasma 17OH-progesterone concentrations determined in untreated $C A H$ infants. A represents a value of $2430 \mathrm{nmol} / \mathrm{l}(826 \mathrm{ng} / \mathrm{ml})$. 
difference in mean plasma $17 \mathrm{OH}$-progesterone concentrations.

\section{Discussion}

This study confirms previous reports of a raised cord plasma 170H-progesterone concentration reflecting placental production of this steroid (Jenner et al., 1970; Lippe et al., 1974; Winter et al., 1976). There are two recent studies which give data on plasma $17 \mathrm{OH}$-progesterone concentrations during the first 24 hours of life of newborn infants (Forest and Cathiard, 1978; Sippell et al., 1978). Both report the rapid fall in plasma levels within hours of birth, reaching a nadir by about 5 to 7 days of age. The results now reported confirm and extend this observation in a larger group of infants also studied during the first week of life. As measurement of plasma $17 \mathrm{OH}$-progesterone is so valuable in the early diagnosis of $\mathrm{CAH}$, a comparison was made between results of plasma $17 \mathrm{OH}$-progesterone determinations in normal and CAH infants. The data clearly show that, by 36 hours' postnatal age, there is a pronounced difference between the two groups.

Congenital adrenal hyperplasia is the most common cause of ambiguous genitalia of the newborn (Hughes, 1977). In many instances, plasma $17 \mathrm{OH}$-progesterone measurements will also aid in the assessment of other conditions. In addition, some infants who are stressed-for example, due to infection-have concentrations of plasma $170 \mathrm{H}-$ progesterone up to $30 \mathrm{nmol} / \mathrm{l}(10 \mathrm{ng} / \mathrm{ml})$ at 5 to 7 days of age. However, plasma $170 \mathrm{H}$-progesterone concentrations exceed $200 \mathrm{nmol} / 1(68 \mathrm{ng} / \mathrm{ml})$ in untreated $\mathrm{CAH}$ infants of this age.

Therefore, determination of plasma $170 \mathrm{OH}-$ progesterone concentrations in the neonatal period can be extremely useful for the differential diagnosis of ambiguous genitalia, electrolyte disturbances, or for the investigation of baby boys with a positive family history for CAH (Hughes and Winter, 1977). It is recommended that plasma samples should be collected after 24 hours' postnatal age in order to eliminate the placental influence on plasma $170 \mathrm{H}-$ progesterone levels. The exact age of the infants, in hours, at the time samples are collected should be known.

We thank Professor O. P. Gray for permission to study infants under his care in the newborn nursery, University Hospital of Wales, and Mr D. W. Wilson for the statistical analyses. The continuing financial support of the Tenovus Organisation is greatly appreciated.

I. A. H. was supported by the Medical Research Council of Canada during part of this study.

\section{References}

Barnes, N. D., and Atherden, S. M. (1972). Diagnosis of congenital adrenal hyperplasia by measurement of plasma 17-hydroxyprogesterone. Archives of Disease in Childhood, 47, 62-65.

Forest, M. G., and Cathiard, A-M. (1978). Ontogenic study of plasma $17 \alpha$-hydroxyprogesterone in the human. I. Postnatal period: evidence for a transient ovarian activity in infancy. Pediatric Research, 12, 6-11.

Hughes, I. A. (1977). Diagnosis and management of congenital adrenal hyperplasia. MD thesis, University of Wales.

Hughes, I. A., and Winter, J. S. D. (1976). The application of a serum $17 \mathrm{OH}$-progesterone radioimmunoassay to the diagnosis and management of congenital adrenal hyperplasia. Journal of Pediatrics, 88, 766-773.

Hughes, I. A., and Winter, J. S. D. (1977). Early diagnosis of salt-losing congenital adrenal hyperplasia in a newborn boy. Canadian Medical Association Journal, 117, 363-365.

Jenner, M. R., Grumbach M. M., and Kaplan, S. L. (1970). Plasma 17OH-progesterone in maternal and umbilical cord plasma in children and in congenital adrenal hyperplasia (CAH): application to neonatal diagnosis of $\mathrm{CAH}$ (abstract). Pediatric Research, 4, 380.

Kemp, K. W., Nix, A. B. J., Wilson, D. W., and Griffiths, K. (1978). Internal quality control of radioimmunoassays. Journal of Endocrinology, 76, 203-210.

Lippe, B. M., LaFranchı, S. H., Lavin, N., Parlow, A., Coyotupa, J., and Kaplan, S. A. (1974). Serum $17 \alpha-$ hydroxyprogesterone, progesterone, estradiol, and testosterone in the diagnosis and management of congenital adrenal hyperplasia. Journal of Pediatrics, 85, 782-787.

Rodbard, D., and Hutt, D. M. (1974). Statistical analysis of radioimmunoassay and immunoradiometric (labelled antibody) assays: a generalised weighted iterative least squares method for logistic curve fitting. In Proceedings of a Symposium on Radioimmunoassay and Related Procedures in Clinical Medicine and Research, Istanbul 1973, p. 165. International Atomic Energy Agency: Vienna.

Sippell, W. G., Becker, H., Versmold, H. T., Bidlingmaier, F., and Knorr, D. (1978). Longitudinal studies of plasma aldosterone, corticosterone, deoxycorticosterone, progesterone, 17-hydroxyprogesterone, cortisol, and cortisone determined simultaneously in mother and child at birth and during the early neonatal period. I. Spontaneous delivery. Journal of Clinical Endocrinology and Metabolism, 46, 971-985.

Tulchinsky, D., and Simmer, H. H. (1972). Sources of plasma $17 \alpha$-hydroxyprogesterone in human pregnancy. Journal of Clinical Endocrinology and Metabolism, 35, 799-808.

Winter, J. S. D., Hughes, I. A., Reyes, F. I., and Faiman, C. (1976). Pituitary-gonadal relations in infancy. II. Patterns of serum gonadal steroid concentrations in man from birth to two years of age. Journal of Clinical Endocrinology and Metabolism, 42, 679-686.

Youssefnejadian, E., and David, R. (1975). Early diagnosis of congenital adrenal hyperplasia by measurement of 17 hydroxyprogesterone. Clinical Endocrinology, 4, 451-454.

Correspondence to $\mathrm{Dr}$ I. A. Hughes, Tenovus Institute, Welsh National School of Medicine, The Heath Cardiff CF4 4XX.

Received 21 September 1978 